\title{
On the dynamics of the electromagnetic parameters of the Northern Tien Shan lithosphere
}

\author{
Elena Bataleva* \\ Research Station of the RAS in Bishkek, 720049, Kyrgyzstan. Bishkek-49
}

\begin{abstract}
The results of geophysical monitoring of seismically hazardous regions are of undoubted interest for studying the deep structure of the lithosphere, regional seismicity, modern geodynamics, etc. The work used experimental material, including the results of magnetotelluric monitoring and the catalogs of the KNET (Kyrgyzstan Telemetered Network), KRNET (Kyrgyz Republic Digital Network) and ISC (International Seismological Center) networks obtained in the seismically active zones of the Bishkek Geodynamic Proving Ground (Northern Tien Shan). The analysis of electromagnetic monitoring results of the Northern Tien Shan seismic generating zone was carried out in a wide frequency range. The data on the parameters of the electromagnetic field of the Earth's crust in the Northern Tien Shan are generalized and systematized. Based on the analysis of these data, the dependence of the response of seismic events in electromagnetic parameters on the distance of earthquake epicenters was studied. The most likely reason for the occurrence of anomalous changes in the electromagnetic field is the activation of deformation processes during the preparation of strong earthquakes. The results of the time-frequency analysis are presented and the features of manifestation are considered depending on the location of the hypo- and epicenters of seismic events and their magnitude. Regularities have been established in the behavior of tipper variations for remote and regional earthquakes for the first quarter of 2016 with an energy class from 6 to 10 .
\end{abstract}

One of the most urgent problems of modern geodynamics is to identify the connection between variations in geophysical fields with seismic processes occurring in the Earth's crust [1-3]. The solution to this problem for the Northern Tien Shan is based on a complex of studies on the territory of the Bishkek Geodynamic Proving Ground (BGPG) (Northern Tien Shan). The geophysical monitoring system of the BGPG consists of: (i) a network of seismological observations based on a network of digital broadband telemetry seismic stations (KNET); (ii) Central Asian GPS Network; (iii) systems of geomagnetic/gravimetric observations and networks of electromagnetic monitoring of changes in the stress-strain state of the Earth's crust by the method of far-field transient electromagnetic sounding (FFES) and by the method of magnetotelluric sounding (MTS).

\footnotetext{
*e-mail: elena.bataleva@gmail.com
} 
The BGPG MT-monitoring system includes: i) two stationary observation points (see Fig. 1) - Ak-Suu and Chon-Kurchak, where the MT-field is continuously recorded on the built-in flash memory of the measuring equipment, the recording duration depends on flash memory size and registration parameters, at the maximum polling frequency, the recording duration is about 20 days, after which the data is copied from the flash memory to the laptop, the equipment is serviced and restarted; ii) a network of profile observations at the Kentor mini-polygon (see Fig. 1, inset on the left); when carrying out specialized MTmonitoring, the measurement mode depends on the research objectives and is seasonal in nature - two sessions (spring and autumn); iii) regime points of MT-monitoring located in the most strain-sensitive zones. The time interval for recording the MT-field ranges from several hours to several days, which determines the depth of soundings.

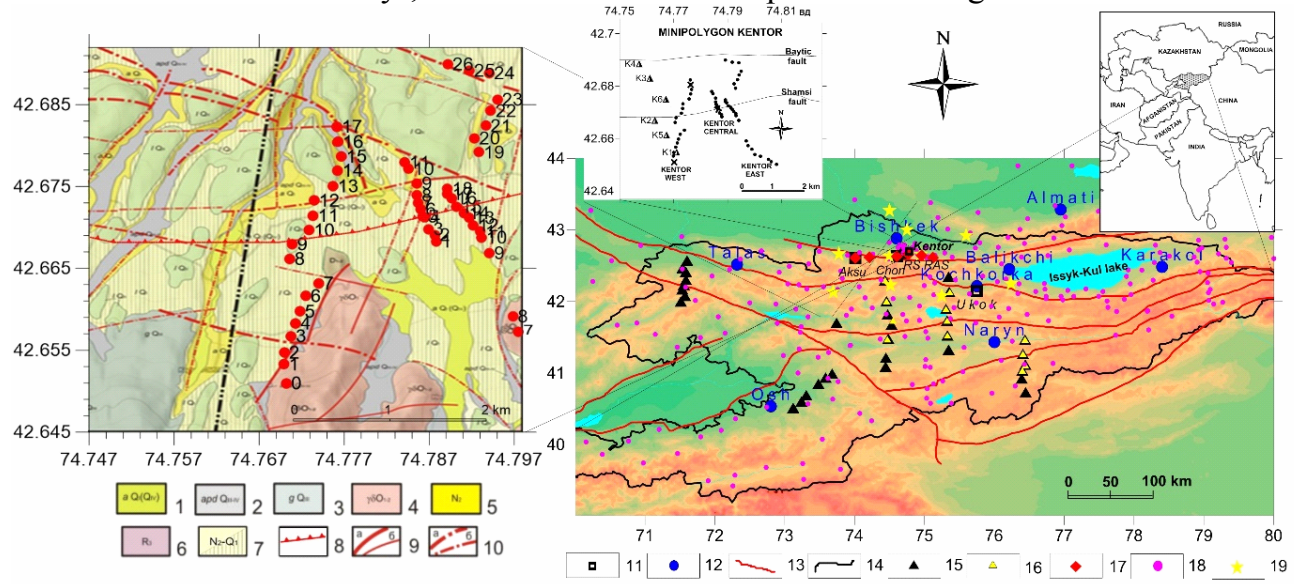

Figure 1. Location map of points of the geophysical monitoring, performed on the territory of the Central Tien Shan: 1 - modern alluvial boulder - pebble deposits; 2 - alluvial boulder - pebble deposits of the first above - flood terrace; 3 - blocky - pebble glacial deposits; 4 - Early and Middle Ordovician granodiorite; 5 - Miocene pebble - crumbly - sandy strata; 6 - Riphean complexes (undivided); 7 - Pliocene-Pleistocene alluvial boulder deposits of the Sharpyldak series; 8 - Shamsi fault; 9 - activated faults and fracture zones of the basement: $\mathrm{a}$ - main; $\sigma$ - secondary; 10 - activated faults assumed under the cover of modern sediments: $a$ - main; $b$ - secondary; 11 - points of stationary and profile magnetotelluric observations; 12 - settlements; 13 - main fault structures; 14 the border of Kyrgyzstan; 15 - points of regime deep MTS; 16 - points of regime deep MTS of 2018; 17 - points of electromagnetic monitoring; 18 - points of the network of GPS observations; 19 KNET teleseismic network sites.

At present, on the territory of the BGPG, a sufficiently large experience has been accumulated in conducting monitoring magnetotelluric (MT) observations in order to study the geodynamic processes occurring deep in the Earth in connection with the preparation of seismic events [4-8]. Reliable geoelectric models of the seismically active junction zone of the Kyrgyz ridge and the Chuy basin have been built on the basis of the performed electromagnetic methods, and interesting practical results of experimental electromagnetic research $[9,10]$, focused on monitoring geodynamic processes in seismically active regions, have been obtained. As a possible prognostic parameter, it is customary to use such a physical characteristic of the geological environment as electrical resistance.

At the moment, the main experimental studies on the territory of the BGPG are aimed at studying the zones of increased fracturing and fluid saturation. When examining such zones by electromagnetic methods, the following factors should be taken into account: i) distribution and orientation of cracks (random distribution of cracks will introduce the least distortion in geophysical fields); ii) the nature of the substance filling the cracks (air, water, debris and clay material, etc.). The presence of fracturing and fractured zones in rocks is 
one of the reasons for electrical anisotropy, i.e. different electrical conductivity in different directions. This factor makes it possible, under favorable conditions, to use the method of azimuthal magnetotelluric monitoring $[4,5]$ to determine the predominant direction of fractured zones and changes in their intensities at different depths.

According to the results, the strike of the dominant vertical or steeply inclined systems of cracks is established - basically this coincides with the distribution of $\rho \mathrm{k}$ and other electromagnetic parameters in polar diagrams [5]. The increased interest in the study of fault zones is associated with their important role in the formation of the stress-strain state of the earth's crust in seismically active regions, the regime of underground fluids, as well as with the processes of mass, heat and energy exchange in the zones of their dynamic influence. These factors also determine a new stage in the development of studies of the nature of deformation processes in the Earth's crust of the BGPG territory.

The method of magnetotelluric sounding, one of the leading methods of electromagnetic monitoring of the Bishkek Geodynamic Proving Ground, allows monitoring of hidden fault structures that do not appear in the sedimentary cover, but are zones of increased fracturing and fluid permeability of the basement and are manifested by anomalies in geophysical fields. Experimental observations by the MT sounding method were carried out using the MTU series equipment from Phoenix Geophysics Ltd (Canada) [11-12]. The 2D smoothing inversion of the BGP MT data was performed using the RodiMackie program. The program implements the nonlinear conjugate gradient method, which attempts to minimize the objective function, which is the sum of the normalized data residuals and model smoothness [13].

In the magnetotelluric method the relationship between the horizontal components of the electromagnetic field is expressed through a pair of linear equations,

$$
\begin{aligned}
& E_{x}=Z_{x x} H_{x}+Z_{x y} H_{y} \\
& E_{y}=Z_{y x} H_{x}+Z_{y y} H_{y} . \\
& \text { In matrix notation this condenses to: } \\
& \mathbf{E}=\mathbf{Z H},
\end{aligned}
$$

where $\mathbf{Z}$ is the magnetotelluric impedance tensor. The MT technique is based on the study of the impedance tensor, i.e. the stationary transfer function relating the horizontal components of the magnetic to the corresponding components of the electric field [14].

To determine the impedance tensor, it is enough to measure 4 components of the electromagnetic field $-E_{x}, E_{y}, H_{x}, H_{y}$. If the observation points additionally record variations in the vertical component of the magnetic field, which is a prerequisite for magnetotelluric soundings performed by the RAS Scientific Station, then you can use the Wiese method with the construction of vectors of the same name. The Wiese vectors (2) are determined by the ratio of three components of geomagnetic variations at one observation point and characterize the inhomogeneity of the distribution of electric currents induced in the Earth, and, consequently, the inhomogeneity of the distribution of electrical conductivity.

$$
H_{z}=W_{z x} H x+W_{z y} H_{y}
$$

They are directed from the conductor perpendicular to the direction of excess currents in it. Wiese vectors (induction arrows, tippers) are constructed from the real (3) and imaginary parts (4) components of the Wiese-Parkinson matrix W:

$$
\begin{aligned}
& \overline{\operatorname{Re} W}=\operatorname{Re} W_{z x} \overline{I_{x}}+\operatorname{Re} W_{z y} \overline{I_{y}}, \\
& \overline{\operatorname{Im} W}=\operatorname{Im} W_{z x} \overline{I_{x}}+\operatorname{Im} W_{z y} \overline{I_{y}} .
\end{aligned}
$$

The vector $\mathrm{ReW}$ is called a real vector. It characterizes the influence of currents that are in phase with the magnetic field. The $\operatorname{ImW}$ vector is called an imaginary vector, it characterizes the influence of reactive excess currents, that is, currents that differ from the 
phase of the horizontal magnetic field by $/ 2$. A distinctive feature of real vectors is that they are directed from zones of increased electrical conductivity to zones of low electrical conductivity. This property of the Wiese vectors makes it possible to localize geoelectric structures characterized by increased or decreased electrical conductivity. In geoelectric models, as a rule, zones of increased electrical conductivity are either zones of dynamic influence of fault structures or areas of increased fracturing. To detect and study fracture zones, both the analysis of traditional electromagnetic parameters (apparent resistivity, impedance phase, etc.) and new ones - anisotropic changes in the electrical conductivity of the geological medium monitoring studies. The geological environment, in general, and the fault structure, in particular, is subject to periodic effects of lunisolar tides, as a result of which its parameters (electrical conductivity, fluid saturation, elasticity, etc.) also periodically change (Fig. 2). Therefore, special attention in this work was paid to the analysis of variations in the magnetic tipper, their relationship with lunisolar tidal effects (Fig. 2) and seismic events (Fig. 3) recorded by various seismic networks.

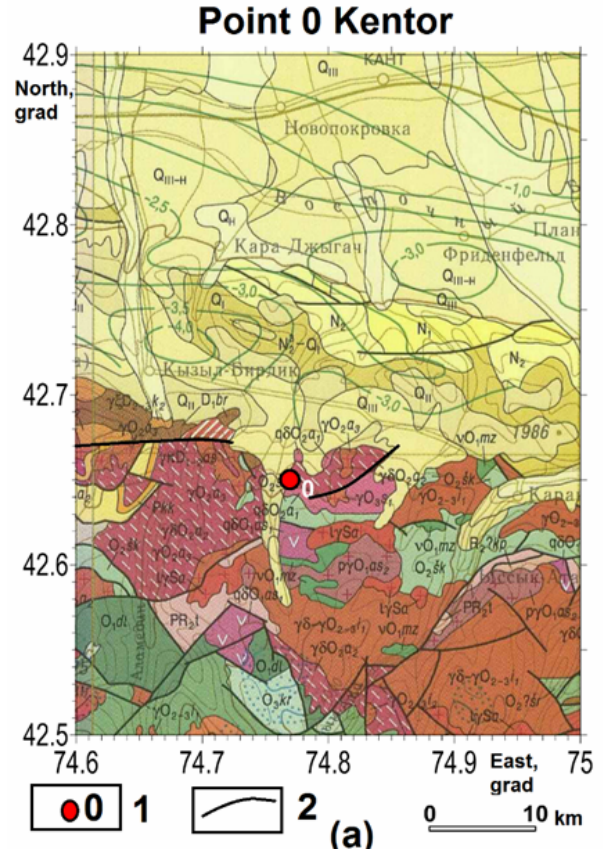

(a)

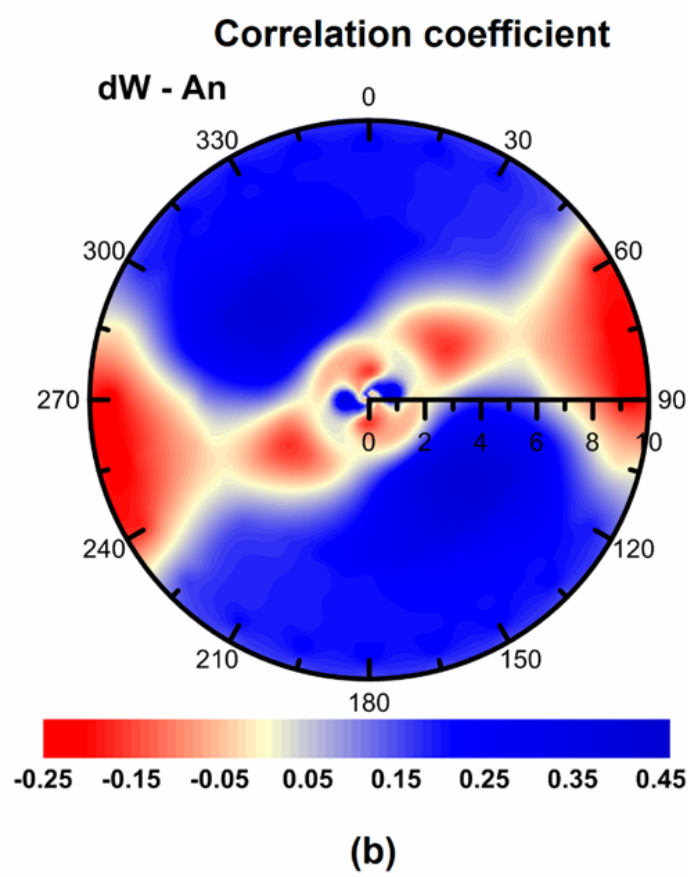

(b)

Figure 2. Correlation polar diagrams for the Kentor mini-poligon: a) - location of monitoring points and faults: 1 - local faults, 2 - MT-monitoring point; b) correlation diagrams for variations of Wiese vectors (dW) at FT-0 and: by the vertical component of lunar-solar tidal effects (An).

Taking into account that real induction arrows $(\mathrm{ReW})$ are associated with active electric currents, and imaginary $(\operatorname{Im} W)$ - with reactive ones, we built and considered the time-frequency series of both parameters $(\operatorname{ReW}$ and $\operatorname{ImW})$. The experimental results obtained indicate that the position of the clusters on the polar correlation diagrams (Fig. 2) is associated with the geoelectric structure of the observation point and corresponds to the orientation of the main tectonic elements in the vicinity of this point. As a result of the analysis of gravitational tidal effects and the behavior of the Wiese vector, it was found that the nature of the relationship depends on the geoelectric structure of the sounding point and is reflected in the distribution of stable clusters on the polar correlation diagrams. It was 
revealed that the orientation of the main tectonic faults (near the sounding point) corresponds to the position of the clusters on the polar correlation diagrams (Fig. 2).

The behavior of variations of real and imaginary induction arrows in a wide range of periods was investigated according to the data of profile magnetotelluric soundings for the Kentor geophysical monitoring minipolygon (Fig. 1) and their relationship with the seismicity distribution was analyzed (Fig. 3). Field experiments have confirmed the concept of the relationship between the stress-strain state of the medium and the change in the apparent electrical resistance through the redistribution of saline solutions between the fracture systems [15-17].

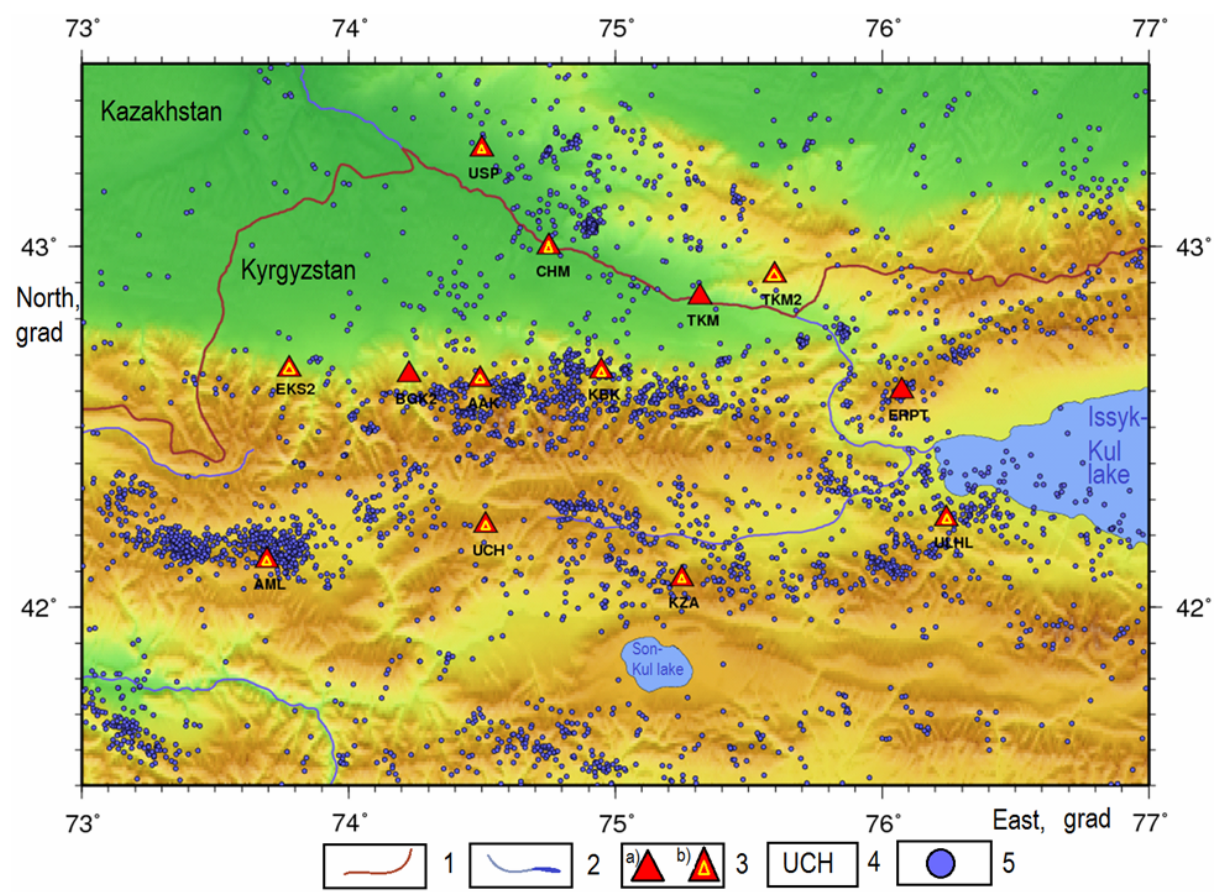

Figure 3. Distribution of earthquake epicenters:

1 - state border of the Kyrgyz Republic; 2 - rivers; 3 - KNET seismic network: a) all seismic stations as of 2000, b) actual working seismic stations as of 2021; 4 - earthquake epicenters.

Figures 4 and 5 show the time-frequency series of the Wiese vector variations for two MT-monitoring stations Ak-Suu and Chonkurchak (Fig. 1), constructed using the azimuthal MT-monitoring method [4,5]. Time-frequency series (TFS) are a form of representing the variability of the structure of the measured components of the electromagnetic field (logarithm of the sounding period) when the coordinate system is rotated by a certain angle (in degrees) [6]. We are considering the difference between the average tipper value (for January-March) and the current one for each azimuth. In both figures, there is a connection between the behavior of events of real induction arrows and the distribution of events for the first quarter of 2016. The energy class of earthquakes that occurred in the Tien Shan over a period of time and recorded by the KNET, KRNET and ISC networks was estimated from 6 to 9.5. As the results of electromagnetic observations in 2016 showed, the arrows $(\mathrm{ReW})$ reflect changes in the stress-strain state of a gea, not only before significant seismic events. In the time-frequency series, the observed anomalous effects are quite comparable in magnitude with the same ones that were noted during the period of preparation for higher-class physical events. The confinement of earthquakes to the gradient zones of 
changes in ReW events is obvious, which allows us to consider the Wiese vector as an informative parameter in the study of geodynamic processes that accompany the safety and security of events.

Noteworthy is the different nature of the real induction arrows for the Ak-Suu and Chon-Kurchak stations. The stations are located in the junction zone of the Kyrgyz ridge and the Chuy basin, in direct contact from the active fault structures - Issyk-Ata and ChonKurchatsky, respectively. The relationship between the behavior of ReW and the seismicity distribution is most clearly manifested in the frequency-time series of $\mathrm{ReW}$, built for the Chon-Kurchak station, although the noise level for it is higher than for the Ak-Suu station.

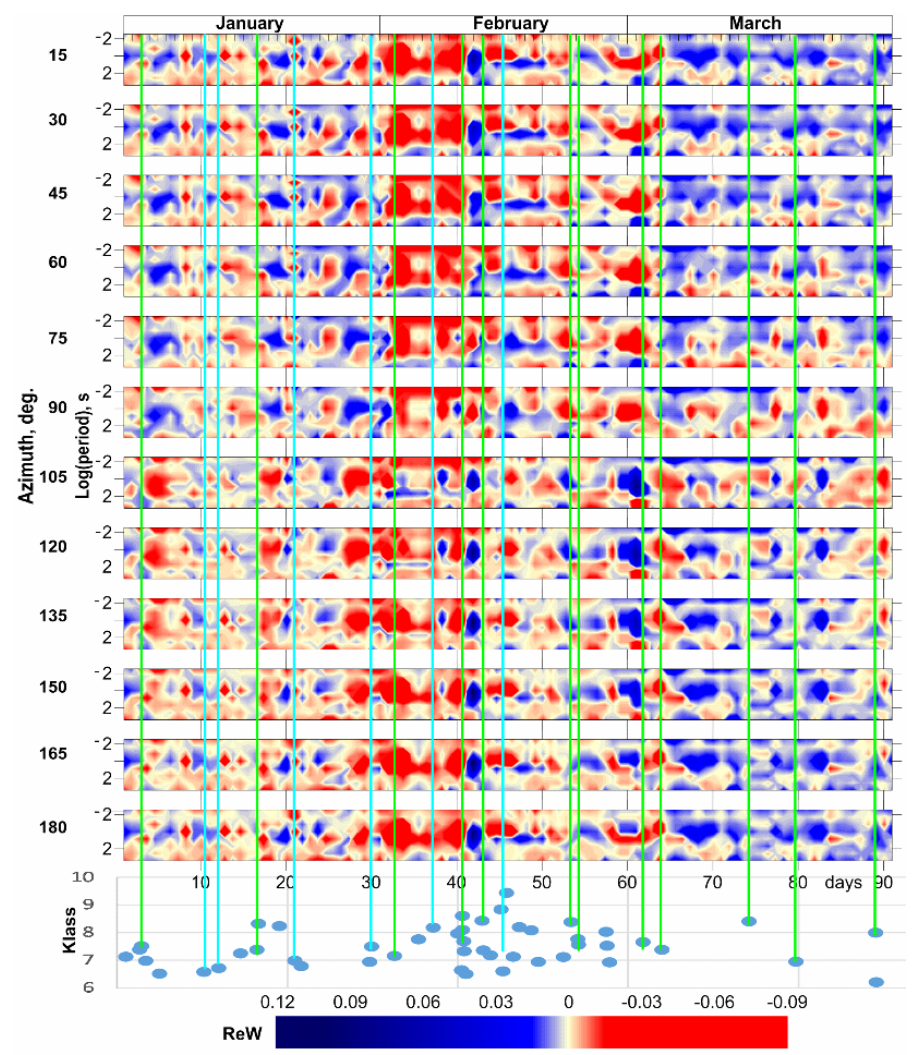

Figure 4. Time-frequency series of the azimuth MT - monitoring (variations of magnetic tipper component) at the Ak - Suu station in comparison with seismicity in January March 2016 (ovals - seismic events).

This can be explained by the higher tensosensitivity of Chon-Kurchak and the closer location of the epicenters of seismic events. The map of the distribution of earthquake epicenters (Fig. 3) indicates that in the immediate vicinity of the Ak-Suu station, the frequency of seismic events is several times lower than for the Chon-Kurchak station. At the same time, the regularity of the reaction of the type of distant and regional earthquakes is not clearly manifested; anomalous variations can be caused by a strong distant event or a close weak one, while the amplitude of the variations can be practically the same.

Thus, an assessment of the characteristics of the stress-strain state of the geological environment and the behavior of variations in electromagnetic parameters was carried out in order to identify patterns in their relationship for seismically active regions of the Tien Shan. The paper summarizes the results of magnetotelluric monitoring on the parameters of the electromagnetic field of the Earth's crust in the Northern Tien Shan. Based on the 
catalogs of the KNET, KRNET and ISC networks, the dependence of the response of seismic events in electromagnetic parameters on the class and distance of earthquake epicenters is studied. The most likely reason for the occurrence of anomalous changes in the electromagnetic field is the activation of deformation processes during the preparation of strong earthquakes. The results of the time-frequency analysis are presented and the features of manifestation are considered depending on the location of the hypo- and epicenters of seismic events and their magnitude. Regularities have been established in the behavior of tipper variations for remote and regional earthquakes for the first quarter of 2016 with an energy class from 6 to 10 .

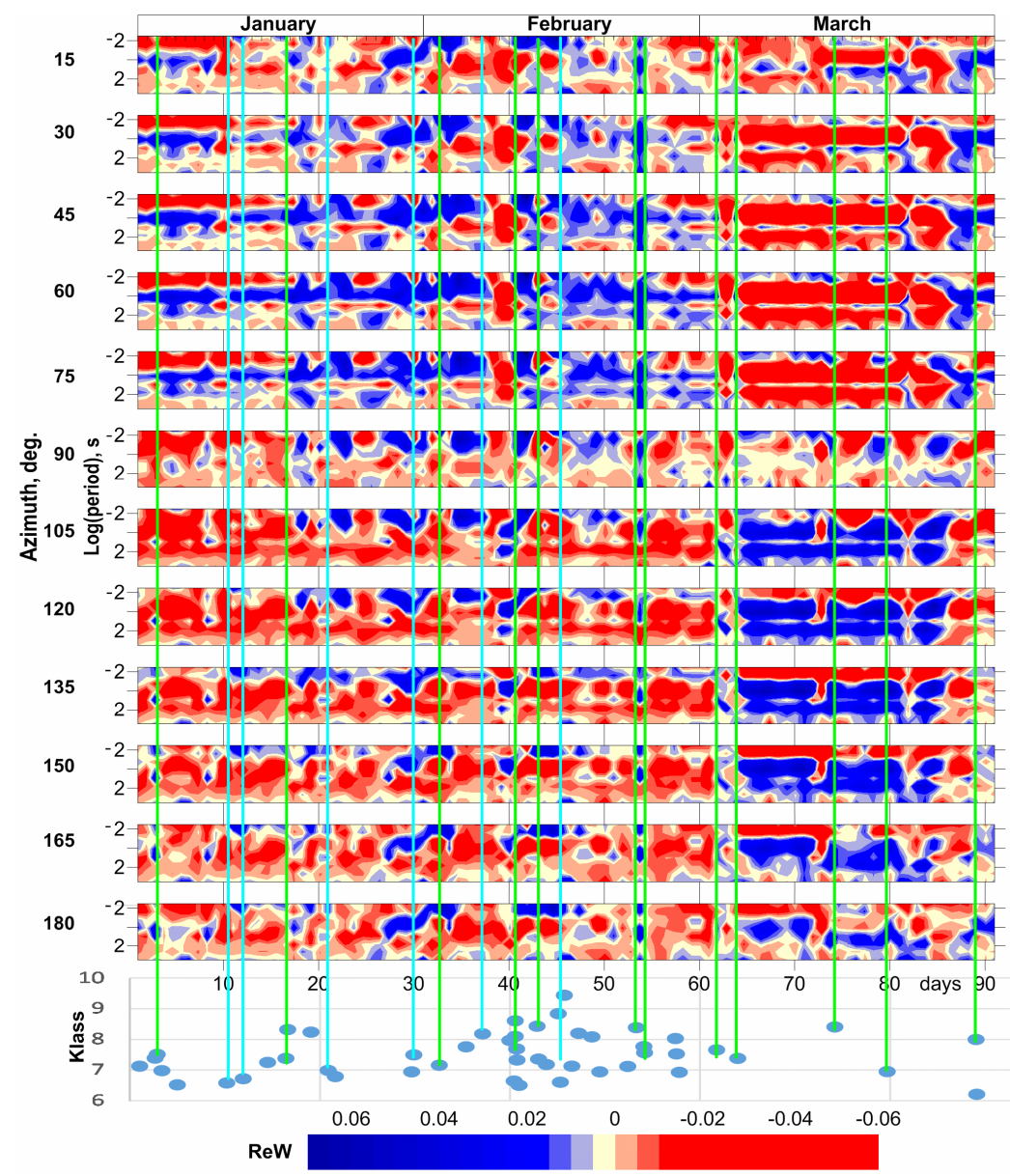

Figure 5. Time-frequency series of azimuth MT-monitoring (tipper variations) for ChonKurchak station in comparison with seismicity for January-March 2016 (ovals - seismic events).

The presented data clearly show that the behavior of such an electromagnetic parameter as a tipper (Wiese vector) can be considered as an indicator of geodynamic processes that accompany the preparation and implementation of seismic events.

The work was carried on the state assignment of the Research Station of the Russian Academy of Sciences in Bishkek (AAAA-A19-119020190063-2). 


\section{References}

1. G.A. Sobolev, N.A. Zakrzhevskaya, J. Volcanol. Seismol. 14 (3), 137-144 (2020).

2. S.K. Park, M.J.S. Johnston, T.R. Madden, F.D. Morgan, H.F. Morrison, Rev. Geophys. 31 (2), 117-143 (1993).

3. D. Stanica, M. Stanica, Acta Geodyn. et Geomater. 4 (1), 99-107 (2007).

4. E.A. Bataleva, V.A. Mukhamadeeva, Geodynam. Tectonophys. 9 (2), 461-487 (2018) (In Russian).

5. E.A. Bataleva, V.Y. Batalev, A.K. Rybin, Izv. Phys. Solid Earth 49 (3), 402-410 (2013).

6. E.A. Bataleva, A.K. Rybin, V.E. Matyukov, Data 4, 99 (2019).

7. B.S. Svetov, S.D. Karinsky, Yu.I. Kuksa, V.I. Odintsov, Phys. Earth 5, 36-46 (1997).

8. A. Rybin, V. Batalev, L. Fox, A. Ingerov, G. Schelochkov, Bulletin KRSU 6 (3), 87-94 (2006).

9. A.K. Rybin, V.V. Spichak, V.Yu. Batalev, E.A. Bataleva, Matyukov V.E., Russ. Geol. Geophys. 49 (5), 337-349 (2008).

10. V.D. Bragin, Active Electromagnetic Monitoring of the Bishkek Prognostic Test Area. PhD Thesis (Candidate of Physics and Mathematics). 135 pp, Moscow (2001) (in Russian).

11. L. Fox, Satellite-Synchronized 3-D Magnetotelluric System. U.S. Patent № 6191 587 B1 (2001)

12. O. Ingerov, Not. Min. Inst. 162, 15-25 (2005).

13. W. Rodi, R. Mackie, Geophys. 66, 174-187 (2001).

14. M.N. Berdichevsky, V.I. Dmitriev Models and Methods of Magnetotellurics, 563 pp, Springer, Berlin (2008).

15. A.A. Zhamaletdinov, F.P. Mitrofanov, A.D. Tokarev, A.N. Shevtsov, Dokl. Earth Sci. 371 (2), 403-407 (2000).

16. L. Bogomolov, V. Bragin, A. Fridman, V. Makarov, G. Sobolev, E. Polyachenko, G. Schelochkov, V. Zeigarnik, A. Zubovich, Tectonophys. 431 (1-4), 143-151 (2007).

17. J.P. Busby, Geoph. Prospect. 48, 677-695 (2000). 